\title{
Prediction of Spontaneous Preterm Birth in At-risk Women Using Thrombospondin 1 from Cervicovaginal Fluid: A Prospective Observational Study
}

\section{Thrombospondin 1 im Zervikovaginalsekret als Prädiktor einer spontanen Frühgeburt bei Frauen mit erhöhtem Risiko: eine prospektive Observationsstudie}

(c) $(1) \Theta$

Authors

Johannes Stubert ${ }^{1}$, Kathleen Gründler ${ }^{2}$, Bernd Gerber ${ }^{1}$, Dagmar-Ulrike Richter ${ }^{1}$, Max Dieterich ${ }^{1}$

Affiliations

1 Department of Obstetrics and Gynecology, Rostock University Medical Center, Rostock, Germany

2 Department of Obstetrics and Gynecology, HELIOS Hospital Schwerin, Schwerin, Germany

Key words

biomarker, cervical length, desmoplakin, preterm birth, preterm labor, stratifin, test characteristics, thrombospondin 1

Schlüsselwörter

Biomarker, Zervixlänge, Desmoplakin, Frühgeburt, vorzeitige Wehen, Stratifin, Testcharakteristika, Thrombospondin-1
received
4. 12.2020
accepted after revision
16.4.2021

Bibliography

Geburtsh Frauenheilk 2021; 81: 1055-1064

DOI 10.1055/a-1486-7148

ISSN 0016-5751

(C) 2021. The Author(s).

This is an open access article published by Thieme under the terms of the Creative Commons Attribution-NonDerivative-NonCommercial-License, permitting copying and reproduction so long as the original work is given appropriate credit. Contents may not be used for commercial purposes, or adapted, remixed, transformed or built upon. (https://creativecommons.org/licenses/by-nc-nd/4.0/)

Georg Thieme Verlag KG, Rüdigerstraße 14,

70469 Stuttgart, Germany

\section{Correspondence}

Johannes Stubert, PhD, MD

Department of Obstetrics and Gynecology,

Rostock University Medical Center

Suedring 81, 18059 Rostock, Germany

johannes.stubert@uni-rostock.de

\section{ABSTRACT}

Introduction Thrombospondin 1, desmoplakin and stratifin are putative biomarkers for the prediction of preterm birth. This study aimed to validate the predictive capability of these biomarkers in patients at risk of preterm birth.

Materials and Methods We included 109 women with symptoms of threatened spontaneous preterm birth between weeks 20 0/7 and 31 6/7 of gestation. Inclusion criteria were uterine contractions, cervical length of less than $25 \mathrm{~mm}$, or a personal history of spontaneous preterm birth. Multiple gestations were also included. Samples of cervicovaginal fluid were taken before performing a digital examination and transvaginal ultrasound. Levels of cervicovaginal thrombospondin 1, desmoplakin and stratifin were quantified by enzyme-linked immunosorbent assays. The primary endpoint was spontaneous preterm birth before $34+0$ weeks of gestation.

Results Sixteen women (14.7\%) delivered before $34+0$ weeks. Median levels of thrombospondin 1 were higher in samples where birth occurred before 34 weeks vs. $\geq 34$ weeks of gestation (4904 vs. 469 pg/mL, p<0.001). Receiver operator characteristics analysis resulted in an area under the curve of 0.86 ( $p<0.0001)$. At an optimal cut-off value of $2163 \mathrm{pg} / \mathrm{mL}$, sensitivity, specificity, positive predictive value and negative predictive value were $0.94,0.77,0.42$ and 0.99 , respectively, with an adjusted odds ratio of 32.9 (95\% Cl: 3.1-345, $\mathrm{p}=0.004$ ). Multiple gestation, cervical length, and preterm labor had no impact on the results. Survival analysis revealed a predictive period of more than eight weeks. Levels of desmoplakin and stratifin did not differ between groups.

Conclusion Thrombospondin 1 allowed long-term risk estimation of spontaneous preterm birth. 


\section{ZUSAMMENFASSUNG}

Einleitung Thrombospondin 1, Desmoplakin und Stratifin sind putative Biomarker für die Vorhersage einer Frühgeburt. Ziel dieser Studie war es, das prädiktive Potenzial dieser Biomarker in Patientinnen mit erhöhtem Frühgeburtenrisiko zu überprüfen.

Material und Methoden Insgesamt wurden 109 Frauen mit Symptomen einer drohenden spontanen Frühgeburt im Zeitraum zwischen 20 0/7 und 31 6/7 SSW in die Studie aufgenommen. Einschlusskriterien waren uterine Kontraktionen, eine Zervixlänge von weniger als $25 \mathrm{~mm}$ oder spontane Frühgeburt in der Anamnese. Mehrlingsschwangerschaften wurden auch eingeschlossen. Es wurde ein zervikovaginaler Abstrich entnommen, gefolgt von einer manuellen und einer Ultraschalluntersuchung. Die zervikovaginalen Konzentrationen von Thrombospondin 1, Desmoplakin und Stratifin wurden mithilfe von ELISA quantifiziert. Der primäre Endpunkt war eine spontane Frühgeburt vor 34 + 0 SSW.
Ergebnisse Bei 16 Frauen (14,7\%) kam es vor 34 + 0 SSW zur Entbindung. Die mittleren Thrombospondin-1-Konzentrationen waren höher in den Proben, bei denen die Geburt unter 34 SSW stattfand, verglichen mit einer Geburt $\geq 34$ SSW (4904 vs. 469 pg/ml, p<0,001). Die ROC-Analyse ergab eine AUC von $0,86(p<0,0001)$. Für den optimalen Cut-off von $2163 \mathrm{pg} / \mathrm{ml}$ betrugen die Sensitivität, Spezifität sowie der positive und negative prädiktive Wert jeweils $0,94,0,77,0,42$ und 0,99 bei einer adjustierten Odds Ratio von 32,9 (95\%-KI $3,1-345, p=0,004)$. Mehrlingsschwangerschaft, Zervixlänge und vorzeitige Wehen hatten keinen Einfluss auf die Ergebnisse. Bei der Überlebensanalyse zeigte sich ein prädiktiver Zeitraum von mehr als 8 Wochen. Es gab keine Unterschiede zwischen den Gruppen hinsichtlich der Desmoplakin- und Stratifin-Konzentrationen.

Schlussfolgerung Thrombospondin 1 erlaubt die langfristige Risikoabschätzung für eine spontane Frühgeburt.

\section{Abbreviations}

$\begin{array}{ll}\text { ART } & \text { assisted reproductive technique } \\ \text { AUC } & \text { area under the curve } \\ \text { CI } & \text { confidence interval } \\ \text { CVF } & \text { cervicovaginal fluid } \\ \text { DSP } & \text { desmoplakin } \\ \text { fFN } & \text { fetal fibronectin } \\ \text { IQR } & \text { interquartile range } \\ \text { NPV } & \text { negative predictive value } \\ \text { OR } & \text { odds ratio }\end{array}$

PAMG-1 placental alpha microglobulin-1

pIGFBP-1 phosphorylated insulin-like growth factor binding protein-1

POCT point-of-care test

PPV positive predictive value

PTB preterm birth

ROC receiver operating characteristics

SFN stratifin

SPTB spontaneous preterm birth

THBS-1 thrombospondin 1

\section{Key Message}

In this study, significantly higher thrombospondin 1 levels were observed in cervicovaginal fluid up to eight weeks before preterm delivery. ROC analysis revealed an AUC of 0.86 ( $p<0.0001$ ) for the prediction of preterm birth before 34 weeks of gestation in at-risk women.

\section{Introduction}

The worldwide burden of preterm birth (PTB) has been estimated to be 14.8 million live-born infants per year, which corresponds to $10.6 \%$ of all births [1]. Fifteen percent of these children are born before week 32 of gestation. In Europe, $57.3 \%$ of neonatal deaths occurred when newborns were delivered before 32 weeks of gestation [2]. Approximately $70 \%$ of PTB occur spontaneously (sPTB) [3]. However, the prediction of sPTB based on clinical symptoms such as uterine contractions or measurement of cervical ripening using digital examination is imprecise and accuracy is poor $[4,5]$. The positive predictive value (PPV) of regular painful uterine contractions for sPTB before 35 weeks of gestation varies between 15 and $25 \%[4,6]$. The risk of delivery is about 18-fold higher compared to the population-based prevalence of PTB of 2.7\% [7]. However, the majority of symptomatic women will not have a PTB. High false-positive rates and low PPV for the prediction of SPTB result in unnecessary treatment which contributes to the low success rates of efforts to reduce the prevalence of SPTB [6, 8]. For example, more than half of the women included in a study on the use of nifedipine for maintenance tocolysis, delivered after 34 weeks of gestation, even if they only received placebo [9].

Cervical length measurement by transvaginal ultrasound has improved the prediction of sPTB, but the overall accuracy of test characteristics remains unsatisfactory $[8,10-12]$. In a meta-analysis, the predictive performance of cervical length measurement in symptomatic women with threatened preterm labor was computed for various cut-off values [13]. A cervical length $<25 \mathrm{~mm}$ increased the probability of sPTB before 34 weeks of gestation from $11.4 \%$ (pre-test probability) to $20.7 \%$, with a sensitivity of $64.3 \%$ [13]. Reduction of the cut-off to $<15 \mathrm{~mm}$ increased the PPV to $62 \%$, but sensitivity declined to $46.2 \%$. Predictive performance is further limited by differences in agreement about the reliability of transvaginal cervical length measurement, with a positive interobserver agreement on a cervical length of $\leq 25 \mathrm{~mm}$ of just $59 \%$ [14].

Risk estimation using biomarkers obtained from cervicovaginal fluid (CVF) has the potential to resolve this dilemma. CVF contains a myriad of proteins, and during pregnancy the biochemical composition CVF is affected by the physiological and pathophysiological changes in the vagina, endocervix, endometrial decidua, adjacent fetal membrane and placenta [15]. The processes involved in 
human labor such as cervical remodeling, myometrial activation or rupture of fetal membranes influence the composition of the CVF [15]. Commercially available point-of-care tests (POCT) of the biomarkers fetal fibronectin (fFN), phosphorylated insulin-like growth factor binding protein-1 (pIGFBP-1) and placental alpha microglobulin-1 (PAMG-1) allow them to be quantified in CVF to estimate the risk of subsequent SPTB. All three proteins originate from the decidua, or rather the chorioamniotic membranes, and are released in great quantities during disintegration of the fetal membranes [16-21]. As this is an event which occurs during the common pathway of parturition [22], these biomarkers have been shown to offer the best results for the short-term prediction of SPTB within 7-10 days, opening a window of opportunity for the administration of antenatal corticosteroid prophylaxis and in-utero transfer of the fetus to a tertiary care center [8, 23, 24]. However, the predictive performance was disappointing, as a direct comparison of cervical length (cut-off: $15 \mathrm{~mm}$ ) with fFN did not result in a better prediction of SPTB within seven days in symptomatic women [23]. Moreover, the use of fFN did not result in a longer duration of pregnancy or a better neonatal outcome [25].

Thus, there is an ongoing need to identify biomarkers which could improve the prediction of sPTB in symptomatic women. A proteome study which analyzed the secretome of human columnar epithelial endocervical cells (End1) and human vaginal cells (Vk2) revealed a panel of 15 candidate biomarkers for PTB [26]. The proteins were tested on previously self-collected CVF specimens from five women with subsequent sPTB between week 28 and week 32 of gestation and five controls who delivered at term. Three proteins were more highly expressed in women with PTB: desmoplakin (DSP) isoform 1 peptide (70.7-fold), stratifin (SFN) peptide (42.4-fold) and the thrombospondin-1 (THBS1) precursor peptide (5.1-fold). The aim of our study was to validate the predictive capability of these candidate biomarkers in the CVF of women at increased risk of sPTB.

\section{Material and Methods}

\section{Study design and participants}

We included women who contacted our tertiary care center (Rostock, Germany) between January 2017 and April 2019 with symptoms of threatened preterm birth. Eligibility criteria were the existence of at least one of the following risk factors for preterm birth between week 20 0/7 and week 31 6/7 of gestation: uterine contractions (>3/30 min or painful labor), cervical length $<25 \mathrm{~mm}$ measured by transvaginal ultrasound, or a personal history of preterm birth or abortion after 16 weeks of gestation. Multiple gestations were allowed. Exclusion criteria were cervical dilatation $>3 \mathrm{~cm}$, previous insertion of an Arabin pessary or surgical cerclage, preterm rupture of membranes, vaginal bleeding, maternal temperature of more than $37.5^{\circ} \mathrm{C}$, vaginal $\mathrm{pH}$ higher than 5 , sexual intercourse during the last $24 \mathrm{~h}$ or vaginal examination in the last $6 \mathrm{~h}$, tocolysis in the previous 7 days, hypertensive disorders, and iatrogenic indication for termination of pregnancy within 7 days after study inclusion. The CVF sample was collected during speculum examination and prior to digital palpation and transvaginal ultrasound of the cervix. Measurement of the cervical length on admission was part of the standard operating procedure of the department.

The condition of the cervix was evaluated by digital palpation and classified using the gestational age-dependent Westin score [27]. A ratio of palpated score/maximum physiological score $>1$ represented preterm maturation of the cervix.

The clinician on duty was responsible for clinical examinations and further treatment decisions, including the indication for tocolysis, corticosteroid prophylaxis, progesterone, cerclage or pessary depending on the clinical situation and subject to national guideline recommendations. PAMG-1, fFN or PIGFBP-1 in the CVF were not analyzed.

The primary outcome was sPTB $<340 / 7$ weeks, including patients with subsequent preterm rupture of membranes. Secondary outcome parameters were sPTB $<37$ 0/7 weeks and delivery within seven days after study enrollment. Gestational age was calculated from the first day of the last menstrual cycle and was corrected based on ultrasound findings if measurements of the crown-rump length in the first trimester differed by more than seven days.

\section{Preparation and processing of CVF samples}

CVF samples were collected using a sterile nylon ${ }^{\circledR}$ flocked swab (ESwap 480C, Copan, Brescia, Italy) that was rotated in the posterior fornix of the vagina. After that, the swab was transferred to a tube filled with $1000 \mu$ l RIPA buffer (Merck, Darmstadt, Germany) containing $10 \mu \mathrm{g}$ aprotinin (Roth, Karlsruhe, Germany). After dilution, the swab was removed and tubes with $250 \mu$ aliquots were stored at $-80^{\circ} \mathrm{C}$ until further processing. To quantify the investigated proteins, the ELISA assays listed in Supporting Information Table S1 were used according to manufacturer's instructions (all from Cloud-Clone Corp., Wuhan, China). Measurements were done in triplicate.

\section{Statistical analysis}

All data were stored and analyzed using the IBM SPSS statistical package 25 (SPSS Inc. Chicago, IL, USA), Excel 2013 (Microsoft Corporation, Redmond, WA, USA) and the R 4.0.0 RStudio statistical software and ggplot2 package. Testing for differences in continuous variables between groups was done using Student's t-test, Mann-Whitney U-test or Kruskal-Wallis test as appropriate; comparisons of categorical variables between groups was done with Fisher's exact test. Survival analysis (time to delivery) was carried out with the Kaplan-Meier method, with statistical comparison of groups done using log-rank test. The impact of multiple gestations, preterm labor, and cervical length $<25 \mathrm{~mm}$ on THBS-1 levels depending on gestational age at delivery (both as fixed factors) was computed with two-factorial ANOVA. All p-values were obtained using two-sided statistical tests, and values $<0.05$ were considered statistically significant.

Receiver operating characteristics (ROC) curves and the area under the curve (AUC) were computed, and the optimal cut-off value (minimal distance to sensitivity and specificity of 1) was calculated using the following equation: (1-sensitivity $)^{2}+(1$-specificity $)^{2}$. To calculate the diagnostic criteria, a second diagnostic cutoff with a specificity of just under 0.9 was selected. A logistic regression model was used to assess the independence of specific 
- Table 1 Patient characteristics.

\begin{tabular}{|c|c|c|c|c|}
\hline Characteristic & $\begin{array}{l}\text { All patients } \\
n=109\end{array}$ & $\begin{array}{l}\text { Delivery }<34 \text { weeks } \\
n=16\end{array}$ & $\begin{array}{l}\text { Delivery } \geq 34 \text { weeks } \\
n=93\end{array}$ & p-value \\
\hline Maternal age, years (mean \pm SD) & $30.4 \pm 4.7$ & $31.0 \pm 4.4$ & $30.3 \pm 4.8$ & $0.597^{*}$ \\
\hline Maternal weight before pregnancy, $\mathrm{kg}($ mean \pm SD) & $70.5 \pm 17.4$ & $82.1 \pm 25.7$ & $68.8 \pm 14.3$ & $0.062^{*}$ \\
\hline Body mass index before pregnancy $(\mathrm{BMI}), \mathrm{kg} / \mathrm{m}^{2}($ mean $\pm \mathrm{SD})$ & $26.5 \pm 16.1$ & $29.4 \pm 9.9$ & $24.4 \pm 4.9$ & $0.063^{*}$ \\
\hline Obesity (BMI $\geq 30$ kg/m²) & $21(19.6 \%)$ & $7(43.8 \%)$ & $14(15.4 \%)$ & $0.015 \ddagger$ \\
\hline Gravidity, n (median, min - max) & $2(1-7)$ & $2(1-7)$ & $2(1-6)$ & $0.230 \dagger$ \\
\hline Parity, n (median, min - max) & $0(0-5)$ & $0(0-5)$ & $0(0-3)$ & $0.470 \dagger$ \\
\hline History of preterm birth, $\mathrm{n}(\%)$ & $21(19.3 \%)$ & $5(31.3 \%)$ & $15(16.1 \%)$ & $0.171 \ddagger$ \\
\hline Multiple gestation, n (\%) & $14(12.8 \%)$ & $8(50.0 \%)$ & $6(6.5 \%)$ & $<0.001 \ddagger$ \\
\hline Assisted reproductive technique, $\mathrm{n}(\%)$ & $11(10.1 \%)$ & $7(43.8 \%)$ & $4(4.3 \%)$ & $<0.001 \ddagger$ \\
\hline Gestational diabetes & $16(14.7 \%)$ & $6(37.5 \%)$ & $10(10.9 \%)$ & $0.014 \ddagger$ \\
\hline Cervical length, mm (median, IQR) & $20.0(14.5-32.5)$ & $14.5(6.0-21.25)$ & $20.0(15.0-34.0)$ & $0.021^{*}$ \\
\hline Cervical length $\leq 25 \mathrm{~mm}, \mathrm{n}$ (\%) & $70(64.2 \%)$ & $14(87.5 \%)$ & $56(60.2)$ & $0.047 \ddagger$ \\
\hline Cervical length $\leq 20 \mathrm{~mm}, \mathrm{n}$ (\%) & $61(56.0 \%)$ & $12(75.0 \%)$ & $49(52.7)$ & $0.111 \ddagger$ \\
\hline Preterm uterine contractions, $\mathrm{n}(\%)$ & $78(71.6 \%)$ & $11(68.8 \%)$ & $67(72.0 \%)$ & $0.771 \ddagger$ \\
\hline Palpatory premature cervix, n (\%) & $53(52.5 \%)$ & $14(87.5 \%)$ & $39(45.9 \%)$ & $0.002 \ddagger$ \\
\hline Gestational age at study inclusion, weeks (median, IQR) & $26(24-29)$ & $26(23.25-28.75)$ & $26(24-29)$ & $0.796 \dagger$ \\
\hline Gestational age at delivery, weeks (median, IQR) & $38(35-39)$ & $30.5(28-31)$ & $39(37-39)$ & $<0.001 \dagger$ \\
\hline Interval to delivery, days (median, IQR) & $76.0(56.5-98.5)$ & $20.5(5.25-48.0)$ & $81.0(63.0-102.5)$ & $<0.001 \dagger$ \\
\hline Preterm rupture of membranes (after study inclusion), $n$ (\%) & $20(18.3 \%)$ & $5(31.3 \%)$ & $15(16.7 \%)$ & $0.178 \ddagger$ \\
\hline Arabin pessary, $\mathrm{n}(\%)$ & $12(11.0 \%)$ & $2(12.5 \%)$ & $10(10.8 \%)$ & $1.000 \ddagger$ \\
\hline Surgical cerclage, $n$ (\%) & $2(1.8 \%)$ & $1(6.3 \%)$ & $1(1.1 \%)$ & $0.278 \ddagger$ \\
\hline Micronized vaginal progesterone, $\mathrm{n}(\%)$ & $77(70.6 \%)$ & $9(56.3 \%)$ & $68(73.1 \%)$ & $0.142 \ddagger$ \\
\hline Tocolysis, n (\%) & $55(50.1 \%)$ & $14(87.5 \%)$ & $41(45.1 \%)$ & $0.002 \ddagger$ \\
\hline Antenatal steroid prophylaxis, n (\%) & $60(55.0 \%)$ & $14(87.5 \%)$ & $46(50.5 \%)$ & $0.006 \ddagger$ \\
\hline
\end{tabular}

outcome parameters. We used a sequential method with the addition of variables in order of magnitude of the crude odds ratios (ORs) and starting with the largest estimate. In the first adjusted model, the covariates "multiple gestation”, "premature cervical ripening", "obesity" and a "history of preterm birth" were included; the second model included the interventional variables "progesterone treatment", "use of an Arabin pessary", "tocolysis" and "antenatal corticosteroid prophylaxis".

We performed a pre-study sample size calculation with a regression model using the statistical G*Power 3.1.9.2 software. The estimated a priori probability for delivery $<34$ weeks was set to $15 \%$, which resulted in a calculated sample size of 139 patients for an assumed post-test probability of $30 \%$, an $\alpha$-error of 0.05 , and a power of $90 \%$. Study recruitment was limited a priori to a period of two years. At this time point, the sample size was 109 patients, which corresponds to a statistical power of $>99 \%$ in a twotailed post-hoc power analysis.

\section{Ethical approval}

This study was conducted as part of the "Analysis of diagnostic accuracy of predictive biomarkers in risk assessment of threatening preterm birth" (ADAPROB) study. The protocol was approved by the local ethics committee of the University of Rostock (IRB-No. A2016-0162), and the study was registered with the German Clinical Trials Register (DRKS-ID: DRKS00010763). Written informed consent was obtained from all participants.

\section{Results}

\section{Characterization of study population}

One hundred and nine women were included in the study. All participants were either symptomatic for preterm birth or had a shortened cervix. None of the women was included based only on a history of preterm birth or abortion. An episode of preterm uterine contractions was the most common reason for consulting a physician ( $n=78,71.6 \%$ ) and for study inclusion ( $>$ Table 1$)$. In women without labor, a cervix $<25 \mathrm{~mm}(\mathrm{n}=26 / 31,83.9 \%)$ was the leading criterion for inclusion. The median gestational age at study entry was 26 weeks (interquartile range [IQR] 24-29) and the median gestation age at delivery was 38 weeks (IQR 35-39). Sixteen women (14.7\%) delivered before 34 weeks and 36 women 

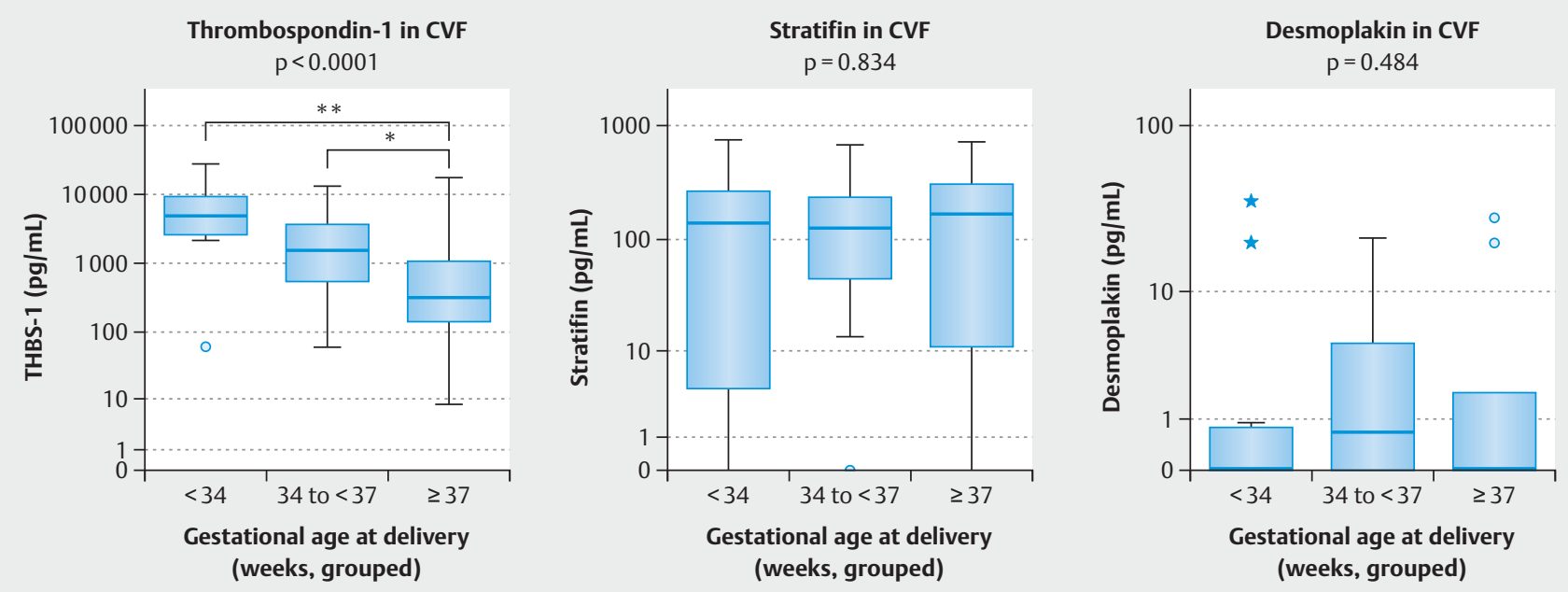

- Fig. 1 Thrombospondin 1, stratifin and desmoplakin protein concentrations in cervicovaginal fluid (CVF) measured by ELISA. Boxplots are grouped by gestational age at delivery. Thrombospondin 1 and stratifin were measured in the total study cohort and subsequently grouped as: $<34$ weeks $(n=16), 34$ to $<37$ weeks $(n=20)$ and $\geq 37$ weeks $(n=73)$; measurement of desmoplakin was restricted to 40 women: $<34$ weeks ( $n=12$ ), 34 to $<37$ weeks $(n=15)$ and $\geq 37$ weeks $(n=13)$. P-values were computed by Kruskal-Wallis test. Post-hoc analysis (Dunn-Bonferroni) for thrombospondin 1 revealed significant intergroup differences between $<34$ weeks and $\geq 37$ weeks (adjusted $p<0.0001={ }^{* *}$ ) and between 34 to $<37$ weeks and $\geq 37$ weeks (adjusted $\mathrm{p}=0.013={ }^{*}$ ).

(33.0\%) before 37 weeks. Six patients (5.5\%) gave birth within seven days, with a median interval between study inclusion and delivery of 2.5 days (IQR $0-6.25$ ). The majority of patients who gave birth before 34 weeks of gestation (62.5\%) delivered after seven days.

\section{Levels of THBS-1, SFN and DSP in CVF}

Median concentrations of THBS-1 in CVF were higher in women with sPTB ( $\triangleright$ Fig. 1). The median concentration was $4904 \mathrm{pg} / \mathrm{mL}$ (IQR 2617-9236) for delivery <34 weeks and $469 \mathrm{pg} / \mathrm{mL}$ (IQR $152-1770)$ for delivery $\geq 34$ weeks ( $<0.001)$. The median level for PTB < 37 weeks was 2633 pg/mL (IQR 925-7058) vs. 314 pg/ $\mathrm{mL}(\mathrm{IQR} 141-1077)$ for delivery $\geq 37$ weeks $(p<0.001)$. There were no correlations between THBS- 1 levels and gestational age at CVF sampling, maternal age, maternal weight or body mass index when only women who delivered at term $(n=73)$ were evaluated. Multiple gestation, preterm labor, and cervical length $<25 \mathrm{~mm}$ had no influence on THBS-1 levels in the two-factorial ANOVA model, neither as a main effect nor in interaction with the time of delivery (Supporting Information, Figs. S1-S3).

The median level of SFN in CVF was $156 \mathrm{pg} / \mathrm{mL}$ (IQR 18-306) and there were no differences between groups with regard to gestational age at delivery (<34 weeks: $141 \mathrm{pg} / \mathrm{mL}$ [IQR 6-318] vs. $\geq 34$ weeks: $167 \mathrm{pg} / \mathrm{mL}$ [IQR 18-306], $\mathrm{p}=0.731)$. DSP was not or only minimally detectable in CVF (median concentration: $0.2 \mathrm{ng} / \mathrm{mL}$ [IQR $0.0-2.8]$ ) irrespective of gestational age at delivery (<34 weeks: $0.0 \mathrm{ng} / \mathrm{mL}$ [IQR $0.0-0.9]$ vs. $\geq 34$ weeks: $0.4 \mathrm{ng} / \mathrm{mL}$ [IQR 0.0-5.5], $\mathrm{p}=0.320)$ ( Fig. 1).

\section{ROC analysis and definition of cut-off values}

ROC and AUCs of THBS-1 for the prediction of PTB < 34 weeks, $<37$ weeks and within seven days were 0.86 (95\% Cl: 0.75-0.96, $\mathrm{p}<0.0001), \quad 0.80$ (95\% Cl: 0.71-0.88, $\mathrm{p}<0.0001)$ and 0.89 (95\% Cl: $0.80-0.98, p=0.001$ ), respectively ( $\mathbf{F i g . 2}$ ). Calculations of test characteristics were based on the optimal (2163 pg/ $\mathrm{mL}$ ) and a diagnostic (4420 pg/mL) cut-off value for the prediction of birth $<34$ weeks. Test characteristics for secondary endpoints were computed using the same cut-offs ( $\triangleright$ Table 2 ). The optimal cut-off was positive in $33.0 \%$ of all women $(n=36 / 109)$, of whom 41.7\% (95\% Cl: 26-58\%) delivered <34 weeks. The diagnostic cut-off was positive in $17.4 \%(n=19 / 109)$, of whom $52.6 \%$ (95\% Cl: $30-75 \%$ ) delivered $<34$ weeks. This corresponds to a positive likelihood ratio of 6.5 ( $95 \% \mathrm{Cl}: 3.1-13.4)$ and a negative likelihood ratio of 0.4 ( $95 \% \mathrm{Cl}: 0.2-0.8$ ). A negative test result decreased the probability from $14.7 \%$ to $7 \%$ for the diagnostic cut-off value and $1 \%$ for the optimal cut-off value. The corresponding unadjusted ORs were 51.4 (95\% Cl: 6.4-412, $\mathrm{p}<0.001)$ for the optimal and 15.6 ( $95 \%$ Cl: 4.6-52.9, $\mathrm{p}<0.001$ ) for the diagnostic cut-off value.

Test characteristics of the endpoint-specific cut-off levels are presented in Supporting Information, Table S2.

\section{Risk factors for PTB and adjusted ORs}

Diagnostic ORs for preterm birth $<34$ weeks were calculated for maternal age $>34$ years, obesity (body mass index $\geq 30 \mathrm{~kg} / \mathrm{m}^{2}$ ), history of PTB, use of assisted reproductive technology (ART), multiple gestation, premature cervical ripening assessed by digital palpation, cervical length $\leq 20 \mathrm{~mm}$, painful uterine contractions (>3/30 min), positive cardiotocography, genital infection with Ureaplasma spp., vaginal dysbiosis, and nulliparity. Of these parameters, ART, multiple gestation, premature cervical ripening and obesity were significantly associated with PTB ( $\bullet$ Fig. 3, Supporting Information Table S3).

Multiple gestation, premature cervical ripening, obesity, and a history of preterm birth were explanatory variables in multiple lo- 


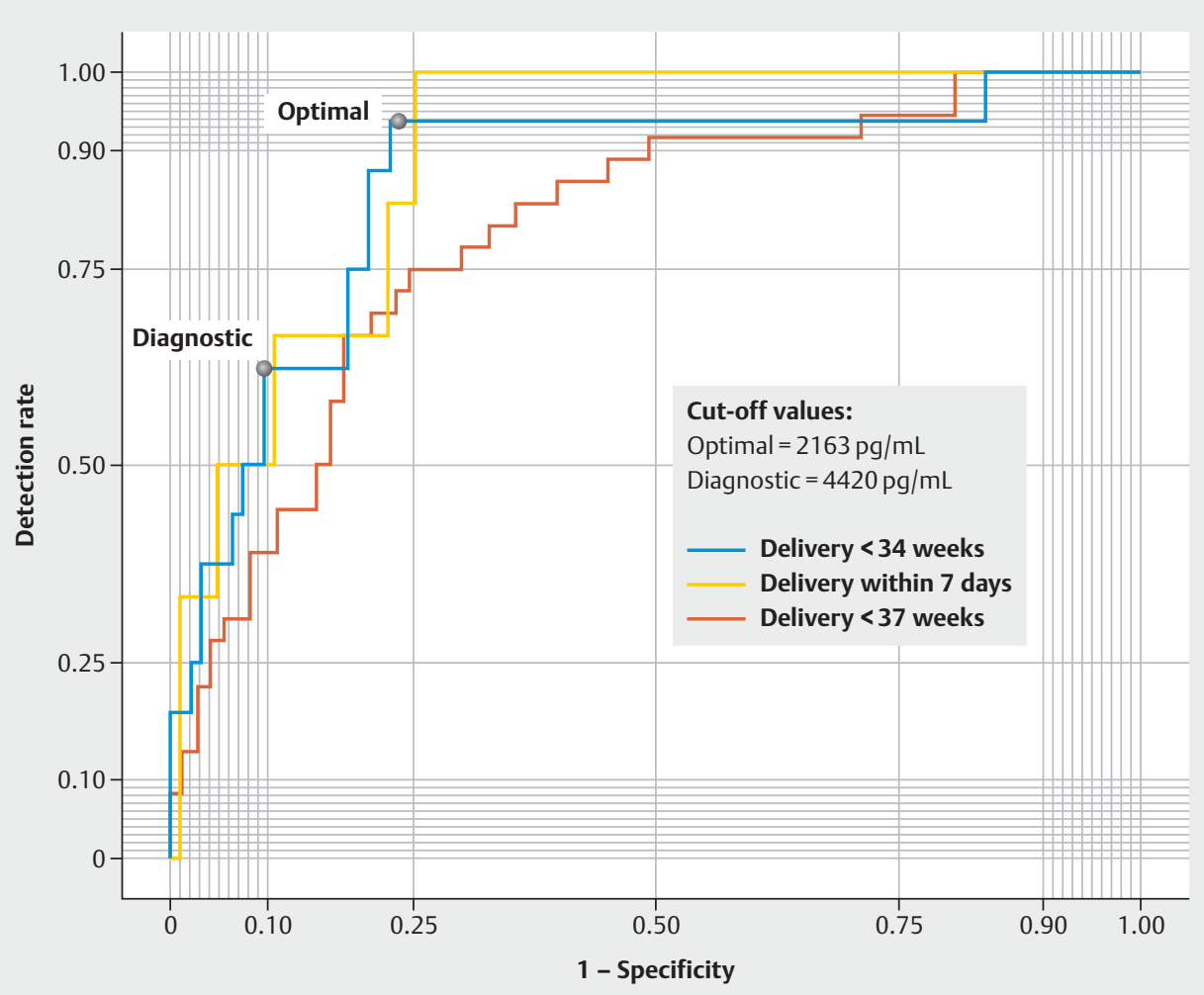

- Fig. 2 Receiver operating characteristics (ROC) curves for the prediction of spontaneous preterm birth in symptomatic women before 34 weeks of gestation (blue line), within 7 days (yellow line) and before 37 weeks of gestation (red line), based on thrombospondin-1 levels. The corresponding areas under the curves are $0.859,0.892$ and 0.795 . The optimal cut-off value for delivery before 34 weeks of gestation corresponds to the point with the minimal distance to a sensitivity and specificity of 1 . The diagnostic cut-off value corresponds to a specificity of 0.9 .

- Table 2 Test characteristics of THBS-1 for the prediction of preterm birth using two different cut-off values. The addition of cervical length to THBS-1 levels did not improve predictive capability.

\begin{tabular}{|c|c|c|c|c|c|c|c|c|}
\hline Endpoint & $\begin{array}{l}\text { Cut-off value } \\
\text { (pg/mL) }\end{array}$ & Sensitivity & Specificity & PPV & NPV & LR+ & LR- & Odds ratio $(95 \% \mathrm{Cl})$ \\
\hline Delivery < 34 weeks & 2163 & 0.94 & 0.77 & 0.42 & 0.99 & 4.2 & 0.1 & $51.4(6.4-412.4)$ \\
\hline Delivery < 37 weeks & 2163 & 0.64 & 0.82 & 0.64 & 0.82 & 3.6 & 0.4 & $8.2(3.3-20.2)$ \\
\hline Delivery within 7 days & 2163 & 1.00 & 0.71 & 0.17 & 1.00 & 3.4 & 0.0 & n.a. \\
\hline Delivery < 34 weeks & 4420 & 0.63 & 0.90 & 0.53 & 0.93 & 6.5 & 0.4 & $15.6(4.6-52.9)$ \\
\hline Delivery < 37 weeks & 4420 & 0.36 & 0.92 & 0.68 & 0.74 & 4.4 & 0.7 & $6.3(2.2-18.5)$ \\
\hline Delivery within 7 days & 4420 & 0.67 & 0.85 & 0.21 & 0.98 & 4.6 & 0.4 & $11.7(2.0-69.8)$ \\
\hline Delivery < 34 weeks & $\begin{array}{l}4420 \\
\text { or } C L<14 \mathrm{~mm}\end{array}$ & 0.81 & 0.74 & 0.35 & 0.96 & 3.2 & 0.3 & $12.5(3.3-47.5)$ \\
\hline Delivery < 34 weeks & $\begin{array}{l}2163 \\
\text { and } C L<25 \mathrm{~mm}\end{array}$ & 0.81 & 0.83 & 0.45 & 0.96 & 4.7 & 0.2 & $20.9(5.3-81.7)$ \\
\hline Delivery < 34 weeks & $\begin{array}{l}2163 \\
\text { and } C L<20 \mathrm{~mm}\end{array}$ & 0.69 & 0.84 & 0.42 & 0.94 & 4.3 & 0.4 & $11.4(3.5-37.7)$ \\
\hline Delivery < 34 weeks & $\begin{array}{l}2163 \\
\text { and } C L<14 \mathrm{~mm}\end{array}$ & 0.50 & 0.91 & 0.50 & 0.91 & 5.8 & 0.5 & $10.6(3.1-36.0)$ \\
\hline
\end{tabular}

n. a. = not available, $\mathrm{Cl}$ = confidence interval, $\mathrm{CL}=$ cervical length, $\mathrm{LR}+=$ positive likelihood ratio, $\mathrm{LR}-=$ negative likelihood ratio, $\mathrm{PPV}=$ positive predictive value, $\mathrm{NPV}=$ negative predictive value 
gistic regression analysis and improved the predictive model ( $\triangleright$ Fig. 4). The remaining parameters did not fit the model and were excluded from analysis. ART showed multicollinearity with multiple gestation and was also removed. After adjustment, THBS-1 remained a significant independent predictor of PTB with an adjusted OR of 32.9 (95\% Cl: 3.1-345, $\mathrm{p}=0.004)$ for the optimal and $12.3(95 \% \mathrm{Cl}: 3.1-71.6, \mathrm{p}=0.005)$ for the diagnostic cutoff value.

In the second adjustment model, the following variables of treatment were added: application of vaginal progesterone, tocolysis, use of an Arabin pessary, and corticosteroid prophylaxis. In this model, only tocolysis remained a significant explanatory variable, resulting in an adjusted OR of 43.8 (95\% Cl: 5.3-361, $\mathrm{p}<0.001$ ) for the optimal and 12.7 (95\% Cl: 3.5-46, $\mathrm{p}<0.001$ ) for the diagnostic cut-off value.

\section{Interval between inclusion in the study and delivery}

Median time-to-delivery interval was 21 days (IQR 6-47) for delivery $<34$ weeks, 51 days (IQR 21-71) for delivery < 37 weeks, and 90 days (IQR 67-108) for delivery $\geq 37$ weeks. Kaplan-Meier plots revealed a nearly linear increase in the risk of delivery $<34$ weeks in THBS-1 test-positive women within an interval of more than eight weeks ( $\triangleright$ Fig. 5). The interval at which $50 \%$ of test-positive women (diagnostic cut-off) delivered $<34$ weeks was 58 days $(8.3$ weeks).

\section{Discussion}

In contrast to DSP and STN, the amount of THBS-1 in CVF was found to be higher in women with subsequent PTB. The quantification was based on an immunodetection assay, which showed a 15 -fold increase in SPTB $<34$ weeks and an 8-fold increase $<37$ weeks compared to delivery at term. Most of the test-positive women had a PTB even if they did not give birth within the first seven days. As THBS-1 allowed subsequent PTB in at-risk women

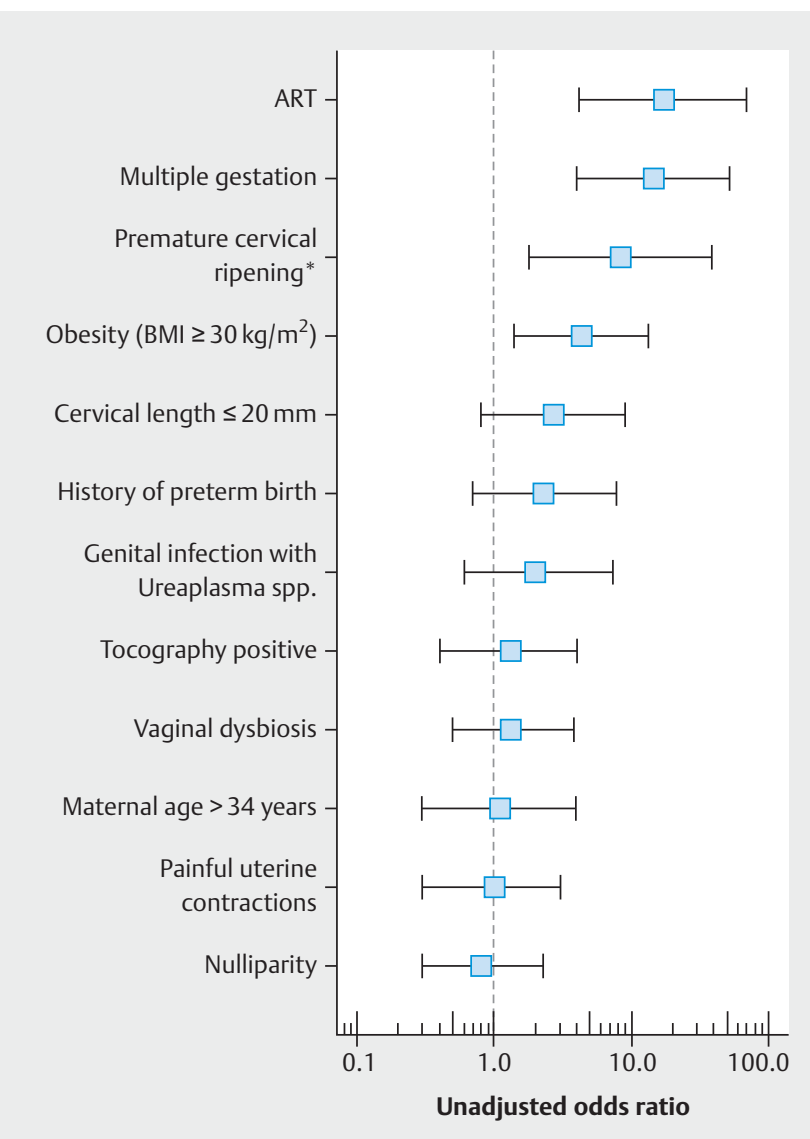

Fig. 3 Analysis of risk factors for preterm birth below 34 weeks of gestation. Shown here are the unadjusted odds ratios (box) with $95 \%$ confidence intervals (whiskers). ART $=$ assisted reproductive technology. ${ }^{*}$ assessed by digital examination and using a gestational age-dependent cervical score.

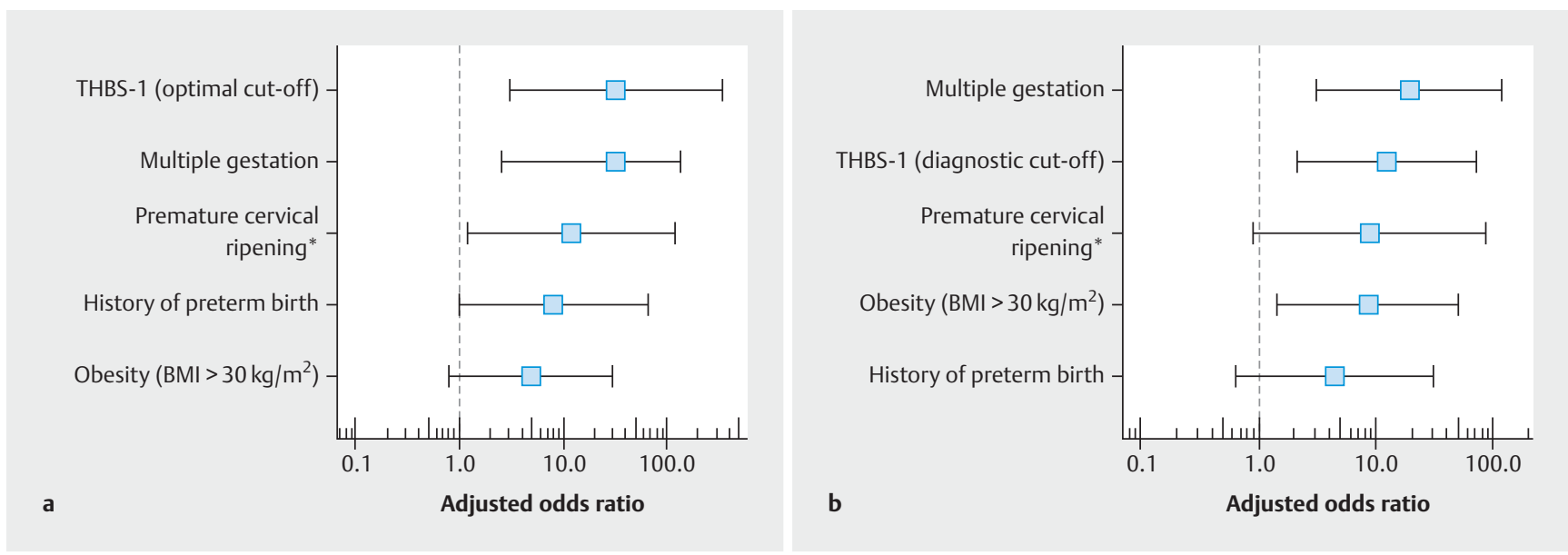

> Fig. 4 Results of the multiple logistic regression analysis. Factors that did not fit the model were excluded. a Results of the model using the optimal THBS- 1 cut-off of $2163 \mathrm{pg} / \mathrm{mL}$, and $\mathbf{b}$ results of the model using the diagnostic THBS- 1 cut-off of $4420 \mathrm{pg} / \mathrm{mL}$. The adjusted odds ratios (box) with $95 \%$ confidence intervals (whiskers) are depicted. THBS-1 = thrombospondin $1,{ }^{*}$ assessed by digital examination and using a gestational age-dependent cervical score. 


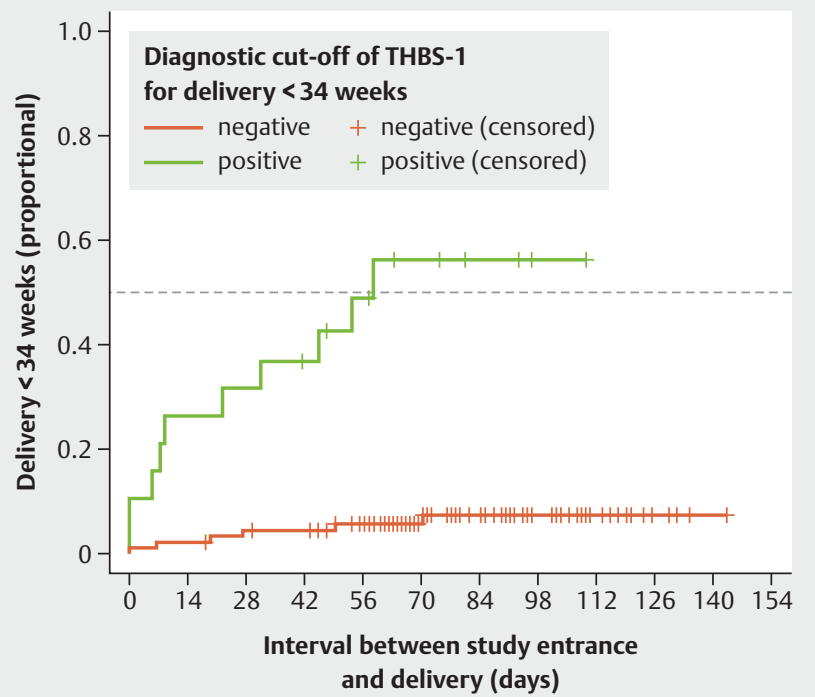

\begin{tabular}{lccccc}
\hline & & \multicolumn{3}{c}{$\begin{array}{c}\text { Mean pregnancy } \\
\text { time between } \\
\text { study inclusion } \\
\text { and delivery in }\end{array}$} & $\begin{array}{c}\text { p-value } \\
\text { days }(\mathbf{9 5 \%} \text { Cl) }\end{array}$ \\
(log-rank)
\end{tabular}

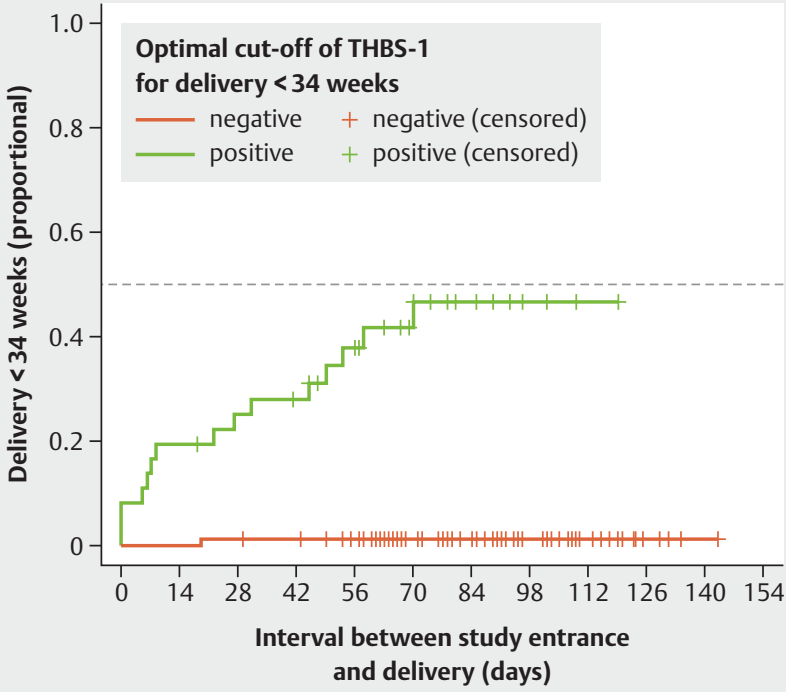

\begin{tabular}{|c|c|c|c|c|c|}
\hline Group & $\begin{array}{l}\text { Number } \\
\text { of cases }\end{array}$ & $\begin{array}{l}\text { Number } \\
\text { of events }\end{array}$ & $\begin{array}{l}\text { Number } \\
\text { censored }\end{array}$ & $\begin{array}{l}\text { Mean pregnancy } \\
\text { time between } \\
\text { study inclusion } \\
\text { and delivery in } \\
\text { days }(95 \% \mathrm{Cl})\end{array}$ & $\begin{array}{c}\text { p-value } \\
\text { (log-rank) }\end{array}$ \\
\hline $\begin{array}{l}\text { THBS-1 } \\
\text { positive }\end{array}$ & 36 & 15 & 21 & $\begin{array}{c}77 \\
(61,93)\end{array}$ & \multirow{2}{*}{$<0.001$} \\
\hline $\begin{array}{l}\text { THBS-1 } \\
\text { negative } \\
\text { b }\end{array}$ & 73 & 1 & 72 & $\begin{array}{c}141 \\
(138,145)\end{array}$ & \\
\hline
\end{tabular}

- Fig. 5 Kaplan-Meier curves showing the risk of preterm birth $<34$ weeks of gestation a using the optimal THBS- 1 cut-off of 2163 pg/mL, and b the diagnostic THBS-1 cut-off of $4420 \mathrm{pg} / \mathrm{mL}$. Patients who delivered $\geq 34$ weeks were censored (indicated by bars). Upper curves correspond to test-positive women. The risk of delivery showed an almost linear increase for the period of more than 8 weeks.

to be identified over the course of more than eight weeks, it seems to be an "intermediate-term" predictor.

The matricellular glycoprotein THBS- 1 is an extracellularly secreted homotrimeric protein which mediates signal transduction between the extracellular matrix and cell surface receptors (e.g., CD47, CD36 and integrins) by binding a variety of ligands [28]. The mature THBS- 1 homomer results from a precursor peptide after removal of the N-terminal signal sequence [29]. THBS-1 is involved in several functional pathways such as anti-angiogenesis, tissue remodeling, inflammation and myometrial contractions [28]. Upregulation of THBS-1 was observed in term labor placenta $[30,31]$ with higher levels of expression in SPTB compared to term birth [32], myometrium in labor [33,34] and cervical ripening with and without labor $[35,36]$. It is detected in CVF and amniotic fluid $[26,37]$. The expression of THBS-1 in the human myometrium is strongly upregulated at the onset of labor at term [34]. Upregulation occurs in both spontaneous and oxytocin-induced labor and is accompanied by deposition of THBS- 1 in the extracellular matrix [34]. In animal models, an upregulation of uterine THBS-1 expression has also been observed in preterm labor [38, 39]. This increase was independent of the etiology of preterm labor and induced by both suspension of progesterone and infection-associated inflammation [39]. Treatment with nimesulide, a selective cox-2-inhibitor, reversed the contraction-dependent effect [38].

A transcriptome analysis of human cervical tissue revealed a 1.6-fold increase of THBS-1 expression following cervical ripening before the onset of labor compared to the unripe cervix at term [36], and vaginal parturition was associated with a 10-fold increase [35]. Sha et al. selected their candidate biomarkers from the standard secreted proteins of a human endocervical (End1) and a human vaginal (Vk2) cell line [26]. In this proteome study, the findings were proven by liquid chromatography and tandem mass spectrometry of five pooled CVF samples collected from asymptomatic women who delivered preterm compared to five term controls [26]. However, a subsequent proteome study from the same laboratory using the same protein candidates was not able to confirm the predictive capacity of THBS-1 [40]. In the nested case-control study, the CVF samples of 33 women with subsequent SPTB $<34$ weeks were compared to 32 term deliveries. CVF samples were previously collected from asymptomatic women with a history of preterm birth between 19 and 23 weeks of gestation. Unfortunately, the authors failed to discuss the putative reasons for the differences in results in more detail. As we only included symptomatic women at risk for PTB, we hypothesize 
that the onset of preterm labor or ripening of the cervix is the critical trigger for the increase of THBS-1 levels.

PAMG-1, fFN and pIGFBP-1 are widely proven biomarkers for the prediction of PTB, and POCT assays for the semi-quantitative detection of these biomarkers in CVF are available [24, 41, 42]. In a recent meta-analysis comparing test characteristics, PAMG-1 was superior to fFN and pIGFBP-1 with corresponding summary ROC and AUCs of $0.96,0.87$ and 0.80 for the endpoint sPTB within 7 days in symptomatic women [24]. In the meta-analysis, PAMG-1 had an overall PPV of $0.76(95 \% \mathrm{Cl}: 0.69-0.84)$ and a sensitivity of 0.76 ( $95 \% \mathrm{Cl}: 0.57-0.89$ ), even if the two largest studies of symptomatic women only showed PPVs between 0.23 and 0.35 and a corresponding sensitivity of $0.50[43,44]$. However, the prevalence of sPTB within seven days was low in both studies (1.3 and $3.2 \%$ ), which may explain the poorer performance. In a recent prospective observational study, the predictive capability of qualitative fFN, quantitative fFN and qualitative PAMG-1 was compared in 128 women with symptoms of preterm labor between 24 and 34 weeks of gestation [45]. The prevalence of sPTB $<34$ weeks was $5.5 \%$ and was therefore lower than in our study (14.7\%). Unexpectedly, PAMG-1 showed a lower predictive accuracy than fFN for the prediction of sPTB $<34$ weeks. PPVs were $17.9 \%$ for qualitative fFN, $20.0 \%$ for quantitative fFN, and only $12.5 \%$ for PAMG-1. The corresponding sensitivities were $71.4 \%$, $71.4 \%$ and $28.6 \%$. The results for qualitative fFN and PAMG- 1 were concordant in $74 \%$. Independently of the different test performances, all results suggest that the predictive capability of PAMG1 , fFN and pIGFBP is optimal within seven days of testing [24]. The increase of these biomarkers seems to be a "late" event during the common pathway of SPTB, limiting the available options to intervene and delay or avoid preterm birth [8]. In contrast, an earlier identification, possibly by THBS-1, might help to initiate interventions (e.g., vaginal progesterone, cerclage or pessary) which could subsequently improve neonatal outcomes by the meaningful prolongation of pregnancy.

One of the strengths of our study is its prospective design and clearly defined inclusion criteria. Inclusion of multiple pregnancies was allowed and, as expected, a significant proportion of preterm births consisted of multiple pregnancies ( $50 \%$ of all deliveries $<34$ weeks). This may be a limitation, but we were not able to identify differences in THBS- 1 levels in CVF for multiple gestations and believe that the collective evaluation was feasible. Previous studies used complex methods for biomarker detection that are not very practicable for routine diagnosis $[26,35,40]$. The use of an immunodetection-based assay in our study suggests that it could have wider clinical applications. Even if the intended sample size of 139 women was missed after two years of inclusion, the definitive results have sufficient statistical power, as was shown in the posthoc analysis. However, the results of our exploratory study did not allow statements regarding test accuracy to be made.

\section{Conclusion}

In the present study, we were able to validate the predictive capability of THBS-1 levels in CVF to estimate the risk of PTB. The results were encouraging, and confirmation in a large multicenter study will be useful.

\section{Funding Information}

The study was funded using our own resources. No funding was received from third parties.

\section{Acknowledgements}

We would like to thank Bianca Gosch for her handling and storage of the CVF samples.

Conflict of Interest

The authors declare that they have no conflict of interest.

\section{References}

[1] Chawanpaiboon S, Vogel JP, Moller AB et al. Global, regional, and national estimates of levels of preterm birth in 2014: a systematic review and modelling analysis. Lancet Glob Health 2019; 7: e37-e46. doi:10.1016/ S2214-109X(18)30451-0

[2] Euro-Peristat Project. European Perinatal Health Report. Core indicators of the health and care of pregnant women and babies in Europe in 2015. November 2018. Accessed April 01, 2021 at: www.europeristat.com

[3] Goldenberg RL, Culhane JF, lams JD et al. Epidemiology and causes of preterm birth. Lancet 2008; 371: 75-84. doi:10.1016/S0140-6736 (08)60074-4

[4] lams JD, Newman RB, Thom EA et al. Frequency of uterine contractions and the risk of spontaneous preterm delivery. N Engl J Med 2002; 346: 250-255. doi:10.1056/NEJMoa002868

[5] Copper RL, Goldenberg RL, Dubard MB et al. Cervical examination and tocodynamometry at 28 weeks' gestation: prediction of spontaneous preterm birth. Am J Obstet Gynecol 1995; 172: 666-671. doi:10.1016/ 0002-9378(95)90590-1

[6] Tsoi E, Fuchs IB, Rane $S$ et al. Sonographic measurement of cervical length in threatened preterm labor in singleton pregnancies with intact membranes. Ultrasound Obstet Gynecol 2005; 25: 353-356. doi:10.1002/uog. 1809

[7] Hufnagel S. Zur Variabilität der Rate Neugeborener mit niedrigem Geburtsgewicht, der Frühgeborenenrate sowie der Hypotrophie- und Hypertrophierate Neugeborener unter Berücksichtigung biologischer Merkmale der Mutter. Analyse des Neugeborenenkollektivs der Jahre 1995-2000 der Bundesrepublik Deutschland [Dissertation]. Rostock, Germany: University of Rostock; 2008. Accessed April 01, 2021 at: http://rosdok.uni-rostock.de/file/rosdok_derivate_000000003962/ Dissertation_Hufnagel_2009.pdf

[8] lams JD, Romero R, Culhane JF et al. Primary, secondary, and tertiary interventions to reduce the morbidity and mortality of preterm birth. Lancet 2008; 371: 164-175. doi:10.1016/S0140-6736(08)60108-7

[9] Roos C, Spaanderman ME, Schuit E et al. Effect of maintenance tocolysis with nifedipine in threatened preterm labor on perinatal outcomes: a randomized controlled trial. JAMA 2013; 309: 41-47. doi:10.1001/jama. 2012.153817

[10] Grobman WA, Lai Y, lams JD et al. Prediction of Spontaneous Preterm Birth Among Nulliparous Women With a Short Cervix. J Ultrasound Med 2016; 35: 1293-1297. doi:10.7863/ultra.15.08035

[11] Pinton A, Severac F, Meyer $N$ et al. A comparison of vaginal ultrasound and digital examination in predicting preterm delivery in women with threatened preterm labor: a cohort study. Acta Obstet Gynecol Scand 2017; 96: 447-453. doi:10.1111/aogs.13071 
[12] Gomez R, Galasso M, Romero R et al. Ultrasonographic examination of the uterine cervix is better than cervical digital examination as a predictor of the likelihood of premature delivery in patients with preterm labor and intact membranes. Am J Obstet Gynecol 1994; 171: 956-964. doi:10.1016/0002-9378(94)90014-0

[13] Sotiriadis A, Papatheodorou S, Kavvadias A et al. Transvaginal cervical length measurement for prediction of preterm birth in women with threatened preterm labor: a meta-analysis. Ultrasound Obstet Gynecol 2010; 35: 54-64. doi:10.1002/uog.7457

[14] Kuusela P, Wennerholm UB, Fadl H et al. Second trimester cervical length measurements with transvaginal ultrasound: A prospective observational agreement and reliability study. Acta Obstet Gynecol Scand 2020; 99: 1476-1485. doi:10.1111/aogs.13895

[15] Heng Y], Liong S, Permezel M et al. Human cervicovaginal fluid biomarkers to predict term and preterm labor. Front Physiol 2015; 6: 151. doi:10.3389/fphys.2015.00151

[16] Lee SE, Park JS, Norwitz ER et al. Measurement of placental alpha-microglobulin-1 in cervicovaginal discharge to diagnose rupture of membranes. Obstet Gynecol 2007; 109: 634-640. doi:10.1097/01.AOG. 0000252706.46734.0a

[17] Westwood M, Gibson JM, Davies AJ et al. The phosphorylation pattern of insulin-like growth factor-binding protein- 1 in normal plasma is different from that in amniotic fluid and changes during pregnancy. J Clin Endocrinol Metab 1994; 79: 1735-1741. doi:10.1210/jcem.79.6.7527409

[18] Sadovsky Y, Friedman SA. Fetal fibronectin and preterm labor. N Engl J Med 1992; 326: 709. doi:10.1056/NEJM199203053261014

[19] Sibille $Y$, Lwebuga-Mukasa JS, Polomski $L$ et al. An in vitro model for polymorphonuclear-leukocyte-induced injury to an extracellular matrix. Relative contribution of oxidants and elastase to fibronectin release from amnionic membranes. Am Rev Respir Dis 1986; 134: 134-140. doi:10.1164/arrd.1986.134.1.134

[20] Rutanen EM, Koistinen R, Wahlstrom T et al. Synthesis of placental protein 12 by human decidua. Endocrinology 1985; 116: 1304-1309. doi:10.1210/endo-116-4-1304

[21] Petrunin DD, Griaznova IM, Petrunina luA et al. [Immunochemical identification of organ specific human placental alphal-globulin and its concentration in amniotic fluid]. Akush Ginekol (Mosk) 1977; (1): 62-64

[22] Romero R, Dey SK, Fisher SJ. Preterm labor: one syndrome, many causes. Science 2014; 345: 760-765. doi:10.1126/science.1251816

[23] Boots AB, Sanchez-Ramos L, Bowers DM et al. The short-term prediction of preterm birth: a systematic review and diagnostic metaanalysis. Am J Obstet Gynecol 2014; 210: 54.e1-54.e10. doi:10.1016/j.ajog.2013. 09.004

[24] Melchor JC, Khalil A, Wing D et al. Prediction of preterm delivery in symptomatic women using PAMG-1, fetal fibronectin and phIGFBP-1 tests: systematic review and meta-analysis. Ultrasound Obstet Gynecol 2018; 52: 442-451. doi:10.1002/uog.19119

[25] Berghella V, Saccone G. Fetal fibronectin testing for reducing the risk of preterm birth. Cochrane Database Syst Rev 2019; (7): CD006843. doi:10.1002/14651858.CD006843.pub3

[26] Shah SJ, Yu KH, Sangar V et al. Identification and quantification of preterm birth biomarkers in human cervicovaginal fluid by liquid chromatography/tandem mass spectrometry. J Proteome Res 2009; 8: 24072417. doi: $10.1021 / \mathrm{pr} 8010342$

[27] Langnickel D. Intensive Überwachung der Schwangerschaft mittels Vorsorgekarte. Dtsch Arztebl 1980; 77: A-1849

[28] Zhao C, Isenberg JS, Popel AS. Human expression patterns: qualitative and quantitative analysis of thrombospondin- 1 under physiological and pathological conditions. J Cell Mol Med 2018; 22: 2086-2097. doi: $10.1111 / \mathrm{jcmm} .13565$
[29] [Anonymous]. Atlas of Genetics and Cytogenetics in Oncology and Haematology. Accessed May 24, 2021 at: http://atlasgeneticsoncology. org/Genes/GC_THBS1.html

[30] Peng HH, Kao CC, Chang SD et al. The effects of labor on differential gene expression in parturient women, placentas, and fetuses at term pregnancy. Kaohsiung J Med Sci 2011; 27: 494-502. doi:10.1016/j.kjms. 2011.06.012

[31] Cindrova-Davies T, Yung HW, Johns J et al. Oxidative stress, gene expression, and protein changes induced in the human placenta during labor. Am J Pathol 2007; 171: 1168-1179. doi:10.2353/ajpath.2007.070528

[32] Chim SS, Lee WS, Ting YH et al. Systematic identification of spontaneous preterm birth-associated RNA transcripts in maternal plasma. PLoS One 2012; 7: e34328. doi:10.1371/journal.pone.0034328

[33] Havelock JC, Keller P, Muleba $\mathrm{N}$ et al. Human myometrial gene expression before and during parturition. Biol Reprod 2005; 72: 707-719. doi:10.1095/biolreprod.104.032979

[34] Morimoto T, Head JR, MacDonald PC et al. Thrombospondin-1 expression in human myometrium before and during pregnancy, before and during labor, and in human myometrial cells in culture. Biol Reprod 1998; 59: 862-870. doi:10.1095/biolreprod59.4.862

[35] Hassan SS, Romero R, Haddad R et al. The transcriptome of the uterine cervix before and after spontaneous term parturition. Am J Obstet Gynecol 2006; 195: 778-786. doi:10.1016/j.ajog.2006.06.021

[36] Hassan SS, Romero R, Tarca AL et al. The transcriptome of cervical ripening in human pregnancy before the onset of labor at term: identification of novel molecular functions involved in this process. J Matern Fetal Neonatal Med 2009; 22: 1183-1193. doi:10.3109/14767050903353216

[37] Isani G, Ferlizza E, Cuoghi A et al. Identification of the most abundant proteins in equine amniotic fluid by a proteomic approach. Anim Reprod Sci 2016; 174: 150-160. doi:10.1016/j.anireprosci.2016.10.003

[38] Wu WX, Zhang Q, Ma XH et al. Suppression subtractive hybridization identified a marked increase in thrombospondin- 1 associated with parturition in pregnant sheep myometrium. Endocrinology 1999; 140: 2364-2371. doi:10.1210/endo.140.5.6697

[39] Haddad R, Romero R, Gould BR et al. Angiogenesis gene expression in mouse uterus during the common pathway of parturition. Am J Obstet Gynecol 2008; 198: 539.e1-539.e8. doi:10.1016/j.ajog.2007.11.021

[40] Parry S, Leite R, Esplin MS et al. Cervicovaginal fluid proteomic analysis to identify potential biomarkers for preterm birth. Am J Obstet Gynecol 2020; 222: 493.e1-493.e13. doi:10.1016/j.ajog.2019.11.1252

[41] Pirjani R, Moini A, Almasi-Hashiani A et al. Placental alpha microglobulin1 (PartoSure) test for the prediction of preterm birth: a systematic review and meta-analysis. J Matern Fetal Neonatal Med 2019. doi:10.1080/14767058.2019.1685962

[42] Conde-Agudelo A, Romero R. Cervical phosphorylated insulin-like growth factor binding protein-1 test for the prediction of preterm birth: a systematic review and metaanalysis. Am J Obstet Gynecol 2016; 214: 57-73. doi:10.1016/j.ajog.2015.06.060

[43] Wing DA, Haeri S, Silber AC et al. Placental Alpha Microglobulin-1 Compared With Fetal Fibronectin to Predict Preterm Delivery in Symptomatic Women. Obstet Gynecol 2017; 130: 1183-1191. doi:10.1097| AOG.0000000000002367

[44] Melchor JC, Navas H, Marcos M et al. Predictive performance of PAMG-1 vs. fFN test for risk of spontaneous preterm birth in symptomatic women attending an emergency obstetric unit: retrospective cohort study. UItrasound Obstet Gynecol 2018; 51: 644-649. doi:10.1002/uog.18892

[45] Dawes LK, Prentice LR, Huang Y et al. The Biomarkers for Preterm Birth Study-A prospective observational study comparing the impact of vaginal biomarkers on clinical practice when used in women with symptoms of preterm labor. Acta Obstet Gynecol Scand 2020; 99: 249-258. doi:10.1111/aogs.13729 